of a previous case of anthrax on the farm, and the outbreak therefore falls into the same category as Nos. I and 9.

As has been already admitted, thirty-nine is too small a number of outbreaks from which to draw a very positive conclusion with regard to the alleged danger of artificial feeding-stuffs as a cause of anthrax, but any unbiassed person will probably concede that the circumstances connected with the series of outbreaks dealt with above deepen the suspicion which already existed, that a considerable number of cases of the disease in this country have an extraneous source of infection, and that the vehicle of infection is not infrequently some artificial food-stuff of which the raw material is derived from a foreign country.

\title{
THE DETECTION OF TUBERCULOSIS IN COWS BY THE EXAMINATION OF EXPECTORATE.
}

\author{
By JOHN RIDDOCH, M.R.C.V.S., Edinburgh.
}

TUBERCULOSIS occurs more frequently in dairy cows than in any other class of animal, this being largely due to their close confinement, and the heavy drain on their systems in the production of milk. The tuberculin test has shown that it exists to the extent of from 20 per cent. upwards, the disease being more common in some districts than others.

In the majority of cases the disease is of small extent, and can only be detected by the tuberculin test. There are two conditions, however, in which the diseased animals are a source of danger: first, when the udder is invaded and tubercle bacilli occur in the milk, and, second, when the lungs are invaded, a condition of more frequent occurrence, and purulent matter containing tubercle bacilli is coughed up and bespatters the wall in front of the animal.

Dried tuberculous sputum blown about in dust is said to be the most frequent means of infection in the human subject, and may not dried purulent matter coughed up by a tuberculous cow and blown about in a byre be a means of infecting the other cows as well as contaminating the milk during milking hours?

When tuberculosis in the udder has advanced to that stage in which an induration can be felt by external palpation, a careful microscopical examination will almost invariably reveal tubercle bacilli in the milk. Indeed, after examining milk from all kinds of abnormal udders for a number of years, I do not remember a case of an indurated tuberculous udder in which by centrifugalizing the milk and carefully examining the deposit tubercle bacilli could not be demonstrated.

It is more difficult to obtain diseased products from the lungs for examination. These products are, however, very frequently available, and afford a means of demonstrating the presence of tubercle even when no other physical symptoms manifest themselves. It is quite true that cows generally swallow their sputum, but if a tuberculous cow is noticed coughing with her head in a horizontal position, her mouth open, and in close proximity to the wall, and if the wall is then carefully scrutinised, small specks of muco-purulent matter will often 
be seen adhering to it. These specks of matter contain tubercle bacilli, and afford a certain means of diagnosing the disease, which, so far as I know, has not hitherto received the attention which it deserves.

Perhaps the best way to show the value of this means of examination is to cite a few of the cases which have happened here within the last few months. (See also Fig. I, Plate IV.)

CASE I.-This was a cow in a byre of forty-eight. She was in rather poorer condition than her neighbours, temperature normal, breathing slightly accelerated. When passing her she was noticed to cough loudly. On proceeding to auscultate the chest two or three patches of muco-purulent matter were noticed on the wall a little above the feeding trough. One of these was scooped up, taken to the laboratory, and microscopically examined. It was found to be very rich in tubercle bacilli. The cow was ordered out of the byre, and slaughtered the following day. The lungs were found to contain a number of cavities (vomicæ) filled with the same kind of matter which the animal had coughed up in the stall, and which bespattered the wall in front of her. The mesenteric glands were enlarged and caseous.

Cavities in the lungs of the cow are, however, not of very common occurrence, but this is not the only condition in which tubercular matter is coughed up, as the following cases will show.

CASE II.-This was a cow in a byre of twenty-seven, and she was in fair condition. She had been off her food, but her appetite had returned. She was said to be recovering from stomach staggers. She had a soft low cough, and after coughing her mouth remained open for a short time. The wall in front of her was carefully scrutinised, and after some search a very small speck of matter was found. It contained tubercle bacilli, but not in great numbers. The cow was ordered out, and killed the following day. Both lungs were congested and full of miliary tubercles. The mediastinal and bronchial glands were enlarged and caseous. The mesenteric glands were slightly affected.

CASE III.-This was an animal exposed for sale as a milk cow. She was only a few days calved, was in good condition, and had a fine appearance of milk. The breathing was considerably accelerated. Some small patches of muco-purulent matter were noticed on the wall in front of the animal, and these on examination were found to contain considerable numbers of tubercle bacilli. This cow was sold to a dairyman, and promptly ordered out of the byre next day, when one quarter of the udder was found to be invaded, the milk containing tubercle bacilli. This cow was taken by the original owner to England!

CASE IV.- This animal was one of a herd of thirty-eight, and was in poorer condition than her neighbours. She was noticed to cough, and on searching the front wall some patches of "sputum" were noticed. On examination these were found to be rich in tubercle bacilli. The animal was slaughtered in a neighbouring slaughterhouse the following day, and the carcase condemned for tuberculosis.

CASE V.-This was one in a byre of twenty-eight cows. She was in good condition: She was said to be "taking her food well, and a grand milker." Her breathing was accelerated, and she was noticed to cough. A search on the front wall revealed some specks of mucopurulent matter, and these on examination were found to contain considerable numbers of tubercle bacilli. The animal was ordered out, 
and killed two days afterwards in a neighbouring slaughterhouse, and the carcase condemned for tuberculosis.

CASE VI.-This was a cow in a byre of eighty. She was in fair condition. She had a cough, and the owner had blistered her throat with mustard. When examining the animal's throat I noticed small patches of "expectorate" on the wall. One of these was scooped up and examined. It contained large numbers of tubercle bacilli. This cow was ordered out, aud her condition described to the owner, who sent her to the knackery the following day.

CASE VII.-This was a cow in a byre of seven. She had been off her feed, and was put into a stall by herself. Some mucopurulent matter was noticed on the animal's back which she had coughed up in the act of licking herself. This matter was very rich in tubercle bacilli. The cow was ordered out, and slaughtered the following day. Both lungs were full of miliary tubercles; they also contained softened caseous matter in several places. The mesenteric glands were enlarged and caseous. One quarter of the udder was invaded, but the teat had been amputated and no milk could be obtained from that quarter.

CASE VIII.-This was a cow seized in the fat stock sale. She coughed occasionally with a loud strong cough. She was in good condition and had a glossy coat. Some specks of matter were found on the wall, and these contained tubercle bacilli. The owner of this cow was so confident that she was free from disease that he got two veterinary surgeons to attend at her slaughter on his behalf. The pleura and peritoneum were covered with granular tubercle, and the lungs contained softened caseous matter. The mediastinal glands were enlarged and caseous. The mesenteric glands were also invaded.

CASE IX.-This was a cow in a byre of ten. There was slight heaving of the flanks, and her temperature was $104^{\circ} \mathrm{F}$. One small patch of expectorate was noticed on the wall. On examination this was found to contain tubercle bacilli. The owner said he had never seen anything amiss with the cow, and that she was milking well. She was immediately ordered out, and was slaughtered two days afterwards. The lungs of this animal were badly affected, and the mesenteric glands were enlarged and caseous. The pleura, peritoneum, and other organs were entirely free.

CASE X. - This was a cow in a byre of twenty. The owner drew my attention to this animal, as she had improved so much since my last visit. On approaching the cow to examine her more closely, I noticed two small spots of expectorate on the wall, and these on examination showed tubercle bacilli. The cow did not cough during the time I was in the byre. The owner of this animal refused to believe that there was anything amiss with her. She was ordered out, and slaughtered the following day. The lungs contained a number of caseous centres, and a mass of tubercular deposit about eight inches in diameter was adhering to the right costal pleura.

CASE XI.-This cow was ravenously eating turnips during my visit, and on passing behind her I noticed her cough; this led to an examination of the front wall. Several patches of matter were observed, and these were found to contain large numbers of tubercle bacilli. This cow was ordered out, and finally sent to England. 
CASE XII.-This was a cow in a byre of sixteen. Her breathing was accelerated, and after watching her for a short time she was noticed to cough. An examination of the front wall revealed some specks of matter, and these on examination showed tubercle bacilli. The owner of this animal was indignant when he was told that the cow was tuberculous. He maintained that she was in perfect health and a heavy milker. She was ordered out, and was slaughtered two days afterwards. The lungs contained a quantity of softened caseous matter throughout their substance. The mediastinal and bronchial glands were enlarged and caseous; the mesenteric glands were about the size of hens' eggs and contained caseous matter. The other organs were not invaded.

In the above cases the expectorate was carefully scooped up in a piece of paper torn from a note-book; the paper was then rolled into a scroll and placed in a sterilised test tube, the test tube being closely corked to prevent desiccation during transit to the laboratory.

More cases might be cited, but these will suffice, the object of this paper being to show the value of this method of examination.

A cow will occasionally cough up purulent matter in other conditions than tubercle, such as a common catarrh, but an examination of the expectorate in these cases will show only catarrhal cells and the complete absence of tubercle bacilli.

[I have had an opportunity to examine Mr Riddoch's preparations, and can vouch for the accuracy of his observations. It may be well to add that there is here no question of "grass bacilli," as the preparations show that the bacilli always occur together with well-staining leucocytes and other cells derived from the lesions or from the air-passages. $-J$. M'F.].

\section{A FURTHER NOTE WITH REGARD TO THE STAINING REACTION OF ANTHRAX BLOOD WITH METHY- LENE-BLUE.}

By J. M'Fadyean, Royal Veterinary College, London.

IN this Journal for March last (p. 35) I described the peculiar colour reaction which is obtained when an imperfectly fixed film of blood containing anthrax bacilli is stained with aqueous solution of methylene-blue. The fact that such a peculiar and striking reaction was obtainable in this way with anthrax blood had been known to me for a number of years, and during the whole of that time I had never failed to obtain it with more or less distinctness according to the number of bacilli present. It was therefore with some surprise that on a recent occasion I failed to obtain the reaction described with a preparation of anthrax blood in which the bacilli were abundantly present. As this was the first preparation stained with a freshlymade I per cent. solution of Gribler's methylene-blue, it was immediately surmised that the uniform success which had formerly attended the use of the stain must have been due to some impurity in the dye used. This appeared to be the more probable since for a number of years past the solution in use in the Laboratory had been from time to time made from the same stock-bottle of methylene-blue powder. 